\title{
АДАПТИВНЫЙ СОРТ ЯРОВОЙ МЯГКОЙ ПШЕНИЦЫ КРАСНОЯРСКАЯ 12
}

\author{
A.V. Sidorov, N.A. Neshumaeva, L.V. Plekhanova
}

\section{ADAPTIVE VARIETY OF SPRING SOFT WHEAT KRASNOYARSKAYA 12}

Сидоров Александр Васильевич - канд. с.-Х. наук, вед. науч. сотр. отдела селекции Красноярского НИИ сельского хозяйства ФИЦ КНЦ СО РАН, г. Красноярск.

E-mail: asidorovs@list.ru

Нешумаева Надежда Алексеевна - канд. биол. наук, вед. науч. сотр. отдела оценки селекционного материала Красноярского НИИ сельского хозяйства ФИЦ КНЦ СО РАН, г. Красноярск.

E-mail: nneshumaeva@list.ru

Плеханова Людмила Васильевна - канд. с.-х. наук, вед. науч. сотр. отдела оценки селекционного материала Красноярского НИИ сельского хозяйства ФИЦ КНЦ СО РАН, г. Красноярск.

E-mail: plechanova-11967@mail.ru

Copm яровой мягкой пшенищы Красноярская 12 создан в Красноярском НИИСХ методом внутривидовой гибридизации и последующего индивидуального отбора из гибридной популяции, полученной от скрещивания селекционного образца РГ-5-1 и Лютесценс 325 (Алтайский край). Сорт включен в Государственный реестр селекционных достижений с 2015 года по Восточно-Сибирскому региону. Рекомендован для воздельвания в Красноярском и Забайкальском крае, республиках Бурятия, Хакасия, Тыва. Представлены биологические, агрономические, технологические и морфологгические признаки нового сорта. Экспериментальную часть работы проводили на опытных полях Красноярского НИИСХ, расположенных в наиболее засушливой части Красноярской лесостепи. Цель исследований - создать сорт пшеницы, сочетающий высокую продуктивность и устойчивость к недостатку влаги. Стандартный сорт для лесостепной зоны Омская 32, для южных районов Омская 33. Разновидность лютесиенс. Cорт среднеспельй, вегетационный период 78-94 суток. За три года конкурсного сортоиспытания (2010-2012 г2.) средняя урожайность
Sidorov Alexander Vasilyevich - Cand. Agr. Sci., Leading Staff Scientist, Selection Department, Krasnoyarsk Research Institute of Agriculture FRC KRC SB RAS, Krasnoyarsk.

E-mail: asidorovs@list.ru

Neshumaeva Nadezhda Alexeevna - Cand. Biol. Sci., Leading Staff Scientist, Department of Selection Material Assessment, Krasnoyarsk Research Institute of Agriculture FRC KRC SB RAS, Krasnoyarsk.

E-mail: nneshumaeva@list.ru

Plekhanova Lyudmila Vasilyevna - Cand. Agr. Sci., Leading Staff Scientist, Department of Selection Material Assessment, Krasnoyarsk Research Institute of Agriculture FRC KRC SB RAS, Krasnoyarsk.

E-mail: plechanova-11967@mail.ru

зерна у нового сорта составила 29,2 ш/га (от 25,5 до 31,2 u/2а), что на 5,8 u/га выше стандарта Омская 32 и на 5,3 ш/га выше стандарта Омская 33. Сорт Красноярская 12 обладает комплексной устойчивостью к грибным заболеваниям. В условиях Красноярского НИИСХ он проявил устойчивость к бурой ржавчине, пыльной головне, стеблевой ржавчине. По качеству зерна сорт отнесен к ценным пшеницам. Обладает высокой экологической пластичностью. На отдельных сортоучастках Восточной Cuбири прибавки урожая за 2013-2017 г2. составили от 2,1 до 7,2 u/га по сравнению со стандартными сортами. Максимальная урожайность 59,1 шга получена в 2014 году в Республике Хакасия.

Ключевые слова: яровая пшеница, сорт, урожайность, качество зерна, пыльная головня, бурая ржавчина.

The variety of spring soft wheat Krasnoyarskaya 12 was created in the Krasnoyarsk Research Institute of Agriculture by intraspecific hybridization and subsequent individual selection from hybrid population obtained by crossing selection samples RG-5-1 
and Lutescens 325 (Altai Territory). Since 2015 the variety has been included in the State Register of Selection Achievements for Eastern Siberia Region. It is recommended for cultivation in Krasnoyarsk and Trans-Baykal Regions, the Republics of Buryatia, Khakassia, Tyva. Biological, agronomic, technologi$\mathrm{cal}$ and morphological features of a new variety were presented. Experimental part of the work was carried out on experimental fields of Krasnoyarsk Research Institute of Agriculture located in the aridest part of Krasnoyarsk forest-steppe. The purpose of the research was to create a wheat variety combining high productivity and resistance to moisture deficit. The standard variety for the forest-steppe zone was Omskaya 32, for southern regions - Omskaya 33, Formis lutescens variant. The variety is mid-season; vegetation season lasts 78-94 days. For three years of variety testing (2010-2012), the average yield of new variety was 29.2 c/hectare (from 25.5 to $31.2 \mathrm{c} /$ hectare); this indicator was higher than the standard Omskaya 32 on 5.8 c/hectare and than the standard Omskaya 33 on 5.3 c/hectare. The variety Krasnoyarskaya 12 possesses complex resistance to fungal diseases. Under the conditions of the Krasnoyarsk Research Institute of Agriculture, it showed resistance to leaf rust, loose smut, stem rust. In terms of grain quality, the variety is classified as valuable wheat. It has high environmental plasticity. On individual cultivar plots of Eastern Siberia, the yield increases for 2013-2017, ranged from 2.1 to $7.2 \mathrm{c} /$ hectare compared to standard varieties. The maximum yield of 59.1 c/hectare was obtained in 2014 in the Republic of Khakassia.

Keywords: spring wheat, variety, productivity, grain quality, loose smut, leaf rust.

Введение. Создание и внедрение в производство новых продуктивных сортов позволяет значительно повысить эффеективность сельскохозяйственного производства. С. Бороевич отмечает, что только селекции мы обязаны в ежегодном повышении урожайности приблизительно на 1\% [1]. По данным А.Н. Халипского [2], за 60 лет сортосмены в Красноярском крае прирост урожайности у яровой пшеницы составил 12-15 кг в год, повышаясь в благоприятные годы до 30 кг и снижаясь в экстремальных условиях до 7-9 кг в год. За 46 лет (1959-2005 гг.) продуктивность созданных в Красноярском НИИСХ сортов выросла на 23 \% [3]. Сорт Красно- ярская 12 является очередным подтверждением возможности улучшения пшеницы методами селекции.

Одним из важнейших признаков сорта является адаптация - способность к приспособлению к какой-то определенной среде. Сорта с узкой адаптацией наиболее полно используют агроклиматические ресурсы конкретной экологической точки. Сорта с широкой адаптационной способностью оказываются приспособлены к разнообразным почвенно-климатическим и погодным условиям.

Цель исследований. Создать сорт яровой мягкой пшеницы для условий Восточной Сибири, сочетающий высокую продуктивность и устойчивость к недостатку влаги.

Материалы и методы исследований. Исследования по созданию и оценке сорта проводили в 1999-2012 годах на опытных полях Красноярского НИИ сельского хозяйства, расположенных в центральной части Красноярской лесостепи. Заключительную оценку на зерновую продуктивность проводили в питомнике конкурсного сортоиспытания. Предшественник пар, норма высева - 5 млн всхожих зерен на гектар, почва - чернозем выщелоченный. Учетная площадь для уборки составляла $30 \mathrm{~m}^{2}$, в четырех повторениях.

Полевые исследования проводили согласно методике ГСИ [4]. В качестве стандартов использовали среднеспелые сорта Омская 32 и Омская 33. Оценка селекционного материала на устойчивость к грибным заболеваниям проводилась сектором иммунитета по методикам, разработанным в ВИР [5]; оценка технологических и хлебопекарных качеств зерна - сектором технологической оценки зерна в соответствии с методиками национальных стандартов РФ и методов ИСО. В статье использованы результаты по оценке сорта Красноярская 12 филиалами ФГБУ Госсорткомиссия по Восточной Сибири за 2013-2017 гг.

Результаты исследований и их обсуждение. Сорт яровой мягкой пшеницы Красноярская 12 выведен в Красноярском НИИСХ методом индивидуального отбора из гибридной популяции от скрещивания селекционного образца РГ-5-1 и селекционного образца из Алтайского НИИСХ Лютесценс 325. Подробно родословная представлена на нижеприведенном рисунке. С 
2015 года сорт включен в Государственный реестр селекционных достижений по ВосточноСибирскому региону. Рекомендован для возделывания в Красноярском и Забайкальском крае, республиках Бурятия, Хакасия, Тыва.

Разновидность лютесценс. Колос безостый, пирамидальный, длинный, средней плотности. Колосковая чешуя яйцевидная, неопушенная. Зубец колосковой чешуи короткий, слегка изогнут. Плечо прямое, среднее, киль выражен средне. Зерно полуокруглое, красное, средней крупности (масса 1000 зерен 35-38 г). Соломина прочная, устойчивая к полеганию, средней вы- соты (65-85 см). Листья сизо-зеленые, в период кущения форма куста полупрямостоячая.

Сорт среднеспелый, вегетационный период 78-94 суток. В условиях Красноярского НИИСХ созревает одновременно со стандартом для лесостепной зоны Омская 32 и на 2-3 дня позднее стандарта для южных районов Омская 33. За три года конкурсного сортоиспытания (20102012 гг.) средняя урожайность зерна у нового сорта составила 29,2 ц/га (от 25,5 до 31,2 ц/га), что на 5,8 ц/га выше стандарта Омская 32 и на 5,3 ц/га выше стандарта Омская 33 (табл. 1).
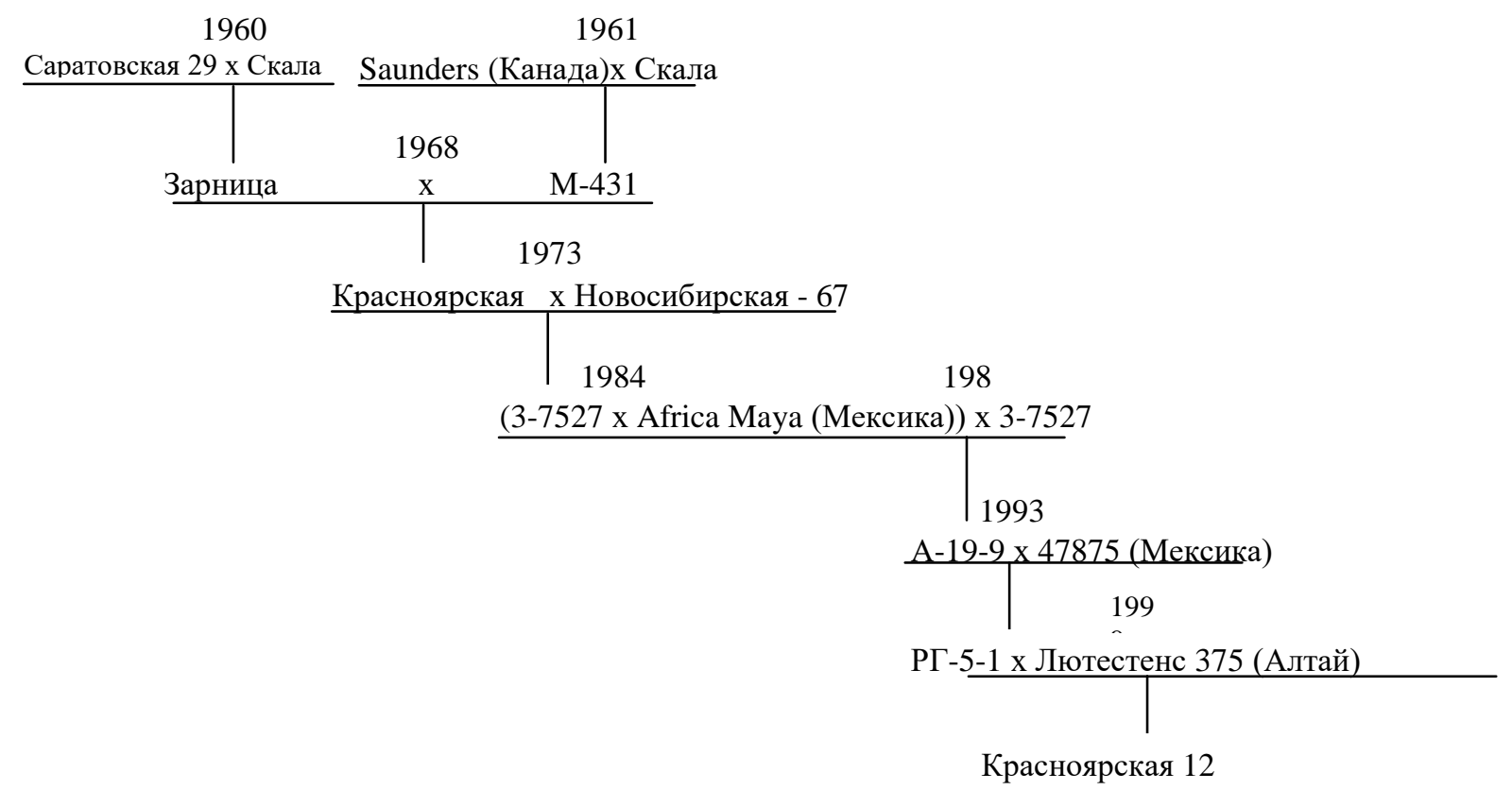

Происхождение сорта мягкой яровой пшеницы Красноярская 12

Красноярская 12 превосходит стандарт Омская 32 по озерненности колоса (на 2,7 шт.) и массе 1000 зерен (на 6,0 грамм), этим и обуславливается высокая урожайность сорта. По сравнению с Омской 33 преимущество достигается за счет большей крупности зерна и густоты продуктивного стеблестоя.

Одним из важнейших показателей сорта является его устойчивость к грибным заболеваниям. Ежегодные потери урожая зерновых культур от грибных болезней составляют 10-15\%, а при эпифитотиях они достигают половины урожая [6]. В среднем за 2006-2010 гг. в России потери урожая зерновых культур от болезней составили 11,3 млн т, или 9,9 \% урожая [7].
Сорт Красноярская 12 обладает комплексной устойчивостью к грибным заболеваниям. В условиях Красноярского НИИСХ он проявил умеренную устойчивость к бурой ржавчине (тип реакции 1-2). По этому показателю он превзошел стандарты Омская 32 (тип реакции 4) и Омская 33 (тип реакции 3-4). Пыльной головней за годы исследования на искусственном инфекционном фоне сорт не поражался. В 2017 г. в условиях Красноярского НИИСХ впервые было отмечено массовое поражение стеблевой ржавчиной. Красноярская 12 проявила достаточно высокий уровень устойчивости к данному заболеванию, что позволило занять первое место по продуктивности в питомнике конкурсного испытания. 
Таблица 1

Продуктивность сорта яровой пшеницы Красноярская 12 (Красноярск, 2010-2012 гг.), ц/га

\begin{tabular}{|l|c|c|c|c|c|}
\hline \multicolumn{1}{|c|}{ Сорт } & $\begin{array}{c}\text { Вегетац. } \\
\text { период, дн. }\end{array}$ & 2010 & 2011 & 2012 & Среднее \\
\hline Омская 32, ст. & 89 & 25,3 & 17,6 & 27,8 & 23,4 \\
\hline Омская 33, ст. & 92 & 22,2 & 21,8 & 27,8 & 23,9 \\
\hline Красноярская 12 & 88 & 31,2 & 25,5 & 31,0 & 29,2 \\
\hline $\mathrm{HCP}_{0,5}$ & & 2,7 & 2,3 & 2,2 & \\
\hline
\end{tabular}

Ценность зерна пшеницы зависит не только от содержания в нем того или иного компонента, но и от его технологических качеств. Качество зерна - довольно широкое понятие, включающее в себя комплекс хозяйственно ценных признаков и свойств, определяющих пищевую и питательную ценность зерна, а также пригодность для технологического использования в пищевой и перерабатывающей промышленности [8].
По отдельным показателям качества зерна Красноярская 12 превосходит стандарт Омская 32, который относится к ценным пшеницам. Сорт превосходит стандарт по массе 1000 зерен, натуре зерна, содержанию белка и клейковины и валометрической оценке, объему хлеба. В то же время сорт несколько уступает стандарту по стекловидности и силе муки при одинаковой хлебопекарной оценке (табл. 2).

\section{Показатели качества зерна яровой пшеницы Красноярская 12 (Красноярск, 2009-2011 гг.)}

\begin{tabular}{|l|c|c|c|}
\hline \multicolumn{1}{|c|}{ Показатель } & Красноярская 12 & Омская 32 & Отклонение \\
\hline Масса 1000 зерен, г & 35,3 & 29,3 & 6,0 \\
\hline Натура, г/л & 776 & 745 & 31 \\
\hline Стекловидность, \% & 47 & 50 & -3 \\
\hline Белок, \% & 14,3 & 13,6 & 0,7 \\
\hline Клейковина, \% & 35,5 & 31,6 & 3,9 \\
\hline Сила муки, е.а. & 410 & 412 & -2 \\
\hline Объем хлеба, мл & 690 & 670 & 20 \\
\hline Общая х/п оценка, балл & 4,0 & 4,0 & - \\
\hline
\end{tabular}

Сорт обладает достаточно стабильными показателями качества. Даже в неблагоприятных погодных условиях качество зерна резко не падает. По данным за 2009-2017 годы, содержание белка варьировало в пределах 14,0-17,7 \%, клейковины 32,8-37,6 \%, сила муки 259-530 е.а., общая хлебопекарная оценка 3,7-4,1 балла. Госсорткомиссией по качеству зерна сорт отнесен к ценным пшеницам.

Таблица 2 
Таблица 3

Результаты испытания сорта Красноярска 12 на сортоучастках Восточной Сибири по пару (2013-2017 гг.)

\begin{tabular}{|l|l|c|c|c|}
\hline \multirow{2}{*}{ Сортоучасток } & \multirow{2}{*}{ Регион } & \multicolumn{2}{|c|}{ Урожай, ц/га } & \multirow{2}{*}{ Отклонение } \\
\cline { 3 - 4 } & & Красноярская 12 & Стандарт & \\
\hline Канский & Красноярский край & 37,2 & Омская 32 - 30,0 & 7,2 \\
\hline Сухобузимский & Красноярский край & 34,8 & Омская $32-28,5$ & 6,3 \\
\hline Нижнеудинский & Иркутская область & 53,7 & Бурятская ост. - 49,3 & 4,4 \\
\hline Иркутский & Иркутская область & 37,0 & Бурятская ост. - 33,3 & 3,7 \\
\hline Саянский & Красноярский край & 19,6 & Омская $32-16,1$ & 3,5 \\
\hline Минусинский & Красноярский край & 41,9 & Омская 33 - 38,8 & 3,1 \\
\hline Боградский & Республика Хакасия & 15,4 & Омская 33 - 12,5 & 2,9 \\
\hline Ширинский & Республика Хакасия & 26,2 & Омская 33 - 23,4 & 2,8 \\
\hline Шилкинский & Забайкальский край & 16,8 & Терция - 14,7 & 2,1 \\
\hline
\end{tabular}

Красноярская 12 обладает высокой экологической пластичностью. Сорт рекомендован к возделыванию в пяти регионах Восточной Сибири. Кроме того, он демонстрирует положительные результаты в различных почвенно-климатических зонах. Например, в Красноярском крае хорошие результаты показаны в подтаежной зоне (Саянский ГСУ), лесостепной зоне (Канский и Сухобузимский ГСУ), в степной зоне (Минусинский ГСУ).

В 2016 г. сотрудники КрасГАУ проводили испытание сортов яровой пшеницы в сухостепной зоне Монголии. Испытывали сорта Красноярская 12, Уярочка (Красноярский НИИСХ), Новосибирская 15 (СибНИРС), Кантегирская 89 (СибНИРС, НИИАП Хакасии), Арвин и Дархан 34 (Монголия). Условия были экстремальными, наблюдались десицит влаги и высокие температуры воздуха и почвы. В этих условиях Красноярская 12 сформировала урожай 20,7 ц/га и превзошла все изучаемые в опыте сорта [9].

Изучение набора сортов и селекционных образцов пшеницы комплексом физиологических и биотехнологических методов в отделе оценки селекционного материала Красноярского НИИСХ позволило характеризовать Красноярскую 12 как сорт с высокой потенциальной продуктивностью и средним уровнем толерантности к таким стресс-фракторам, как засуха и закисление почв [10]. По данным других авторов, сорт обладает высоким уровнем экологической стабильности [11]. Приведенные примеры говорят о высокой адаптационной способности сорта, его способности наиболее полно использовать агроклиматические ресурсы регионов возделывания.
На сорт получены авторское свидетельство № 61063 и патент № 7741 от 4 марта 2015 года. Оригинаторы: ФГБНУ Федеральный исследовательский центр «Красноярский научный центр СО РАН» (660036, г. Красноярск, ул. Академгородок 50); филиал ФГБУ Госсорткомиссия по Красноярскому краю, Республике Хакасия и Республике Тыва (660001, г. Красноярск, ул. Советская, 21).

Патентообладатель: ФГБНУ Федеральный исследовательский центр «Красноярский научный центр СО РАН».

Выводы. В лаборатории селекции пшеницы Красноярского НИИСХ создан новый сорт яровой мягкой пшеницы Красноярская 12, адаптированный к разнообразным природно-климатическим условиям Восточной Сибири. Сорт обладает высокой продуктивностью, устойчивостью к грибным заболеваниям, хорошим качеством зерна. Грамотное его использование позволит повысить уровень урожайности пшеницы и стабилизировать ее уровень по годам.

\section{Литература}

1. Бороевич С. Принципы и методы селекции растений. М.: Колос, 1984. 344 с.

2. Халипский А.Н. Роль экотипа и фона возделывания в эффективности сортосмены полевых культур в Красноярском крае: автореф. дис. ... д-ра с.-Х. наук: 06.01.05. Тюмень, 2009. 32 с.

3. Сидоров А.В. Итоги работы по селекции яровой пшеницы на продуктивность, качество и устойчивость к болезням // Селекция 
сельскохозяйственных культур на устойчивость к экстремальным условиям среды в аридных зонах Сибири: сб. науч. тр. Новосибирск: ГНУ СО Россельхозакадемия, 2012. C.187-195.

4. Методика государственного сортоиспытания сельскохозяйственных культур. Вып. I (общая часть). М. : Колос, 1985. 269 с.

5. Изучение генетических ресурсов зерновых культур на устойчивость к вредным организмам. М. : Россельхозакадемия, 2008. 431 с.

6. Рассел Г.Э. Селекция растений на устойчивость к вредителям и болезням. М. : Колос, 1982. $421 \mathrm{C}$

7. Захаренко В.А. Оценка потенциала фитосанитарии в зерновом производстве России (методики оценки и показатели) // Защита и карантин растений. 2013. № 9. С. 3-7.

8. Плеханова Л.В. Влияние агроэкологических факторов и генотипа сорта на формирование качества зерна мягкой яровой пшеницы в лесостепи Приенисейской Сибири: дис. ... канд. С.-Х. наук. Красноярск, 2009. 140 с.

9. Антонова Н.В., Бопn В.Л., Литвинова В.С. [и др.]. Изучение адаптационного потенциала и элементов технологии пшеницы сибирской селекции с целью разработки рекомендаций по повышению продуктивности агроценозов: отчет о НИР / КрасГАУ. Красноярск, 2016. 40 с.

10. Никитина В.И., Количенко А.А. Оценка экологической стабильности сортов яровой мягкой пшеницы на сортоучастках Красноярского края // Вестник КрасГАУ. 2019. № 3. С. 58-64.

11. Ступко В.Ю, Зобова Н.В., Сидоров А.В. [и др.]. Перспективные способы оценки яровой мягкой пшеницы на чувствительность к эдасрическим стрессам // Достижения науки и техники АПК. 2019. Т. 33. № 10. С. 45-50.

\section{Literatura}

1. Boroevich S. Principy i metody selekcii rastenij. M.: Kolos, 1984. $344 \mathrm{~s}$.
2. Halipskij A.N. Rol' jekotipa i fona vozdelyvanija $\mathrm{v}$ jeffektivnosti sortosmeny polevyh kul'tur $\mathrm{v}$ Krasnojarskom krae: avtoref. dis. ... d-ra s.-h. nauk: 06.01.05. Tjumen', 2009. $32 \mathrm{~s}$.

3. Sidorov A.V. Itogi raboty po selekcii jarovoj pshenicy na produktivnost', kachestvo i ustojchivost' k boleznjam // Selekcija sel'skohozjajstvennyh kul'tur na ustojchivost' k jekstremal'nym uslovijam sredy $\mathrm{v}$ aridnyh zonah Sibiri: sb. nauch. tr. Novosibirsk: GNU SO Rossel'hozakademija, 2012. S.187-195.

4. Metodika gosudarstvennogo sortoispytanija skohozjajstvennyh kul'tur. Vyp. I (obshhaja chast'). M. : Kolos, 1985. 269 s.

5. Izuchenie geneticheskih resursov zernovyh kul'tur na ustojchivost' k vrednym organizmam. M. : Rossel'hozakademija, 2008. $431 \mathrm{~s}$.

6. Rasse/ G.Je. Selekcija rastenij na ustojchivost' k vrediteljam i boleznjam. M. : Kolos, 1982. $421 \mathrm{~s}$.

7. Zaharenko V.A. Ocenka potenciala fitosanitarii $\mathrm{v}$ zernovom proizvodstve Rossii (metodiki ocenki i pokazateli) // Zashhita i karantin rastenij. 2013. № 9. S. 3-7.

8. Plehanova L.V. Vlijanie agrojekologicheskih faktorov i genotipa sorta na formirovanie kachestva zerna mjagkoj jarovoj pshenicy $v$ lesostepi Prienisejskoj Sibiri: dis. ... kand. s.-h. nauk. Krasnojarsk, 2009. $140 \mathrm{~s}$.

9. Antonova N.V., Bopp V.L., Litvinova V.S. [i dr.]. Izuchenie adaptacionnogo potenciala i jelementov tehnologii pshenicy sibirskoj selekcii s cel'ju razrabotki rekomendacij po povysheniju produktivnosti agrocenozov: otchet o NIR / KrasGAU. Krasnojarsk, $2016.40 \mathrm{~s}$.

10. Nikitina V.I., Kolichenko A.A. Ocenka jekologicheskoj stabil'nosti sortov jarovoj mjagkoj pshenicy na sortouchastkah Krasnojarskogo kraja // Vestnik KrasGAU. 2019. № 3. S. 58-64.

11. Stupko V.Ju, Zobova N.V., Sidorov A.V. [i dr.]. Perspektivnye sposoby ocenki jarovoj mjagkoj pshenicy na chuvstvitel'nost' $k$ jedaficheskim stressam // Dostizhenija nauki i tehniki APK. 2019. T. 33. № 10. S. 45-50. 